\title{
Interactions of Steroid, Methotrexate, and Radiation Determine Neurotoxicity in an Animal Model to Study Therapy for Childhood Leukemia
}

\author{
PHYLLIS J. MULLENIX, WILLIAM J. KERNAN, ANN SCHUNIOR, ANTHONY HOWES. \\ DEBORAH P. WABER. STEPHEN E. SALLAN. AND NANCY J. TARBELL
}

\begin{abstract}
Department of Toxicolog!: Forsyth Research Institute, Boston. 1/assachusetts (2)115 /P.J.1/. A.S./: Department of Radiation Oncolog.: Joint C'enter for Radiation Therapy /P.J.H. . A.H. N.J.T.J. and Department of Psychiatr. [D.P.W.J. Harvard Medical School. Boston. Massachusetts 122115: Department of Pediatric Oncology: DanaFarher Cancer Institute/S.E.S.J. Boston. Massachusetts 02115; and V'terinary Diagnostic Laboratory. C'olle'ge' of l'eterinary Medicine. Iow'a State University, Ames. Iowa 50011 /W.J.K.I
\end{abstract}

\begin{abstract}
Children with leukemia receive CNS therapy to improve long-term survival. Neurotoxic effects, such as cognitive impairment, have been associated with this therapy. A rat model was developed to determine which agent, or combination of agents, in CNS therapy causes neurotoxicity. The agents examined were cranial irradiation $(1000$ cGy), methotrexate ( 2 or $4 \mathrm{mg} / \mathrm{kg}$, intraperitoneally), and prednisolone (18 or $36 \mathrm{mg} / \mathrm{kg}$, intraperitoneally). Young Sprague-Dawley rats were exposed to each agent alone or to two- or three-agent combinations. Each therapy had matched controls that received sham radiation and/or intraperitoneal saline. Subsequent to exposure, spontaneous behavior was tested using a computer pattern recognition system, which recorded and classified behavior in a novel environment. Behavioral initiations, total times, and time structures were compared in therapy and control groups. Combined rather than single-agent therapies had more behavioral effects, and these were dose- and sex-dependent. Synergistic interactions between agents caused behavioral deficits, and components of the combination determined the abnormality. Some combinations interacted antagonistically, and thus mitigated behavioral deficits. Prednisolone was clearly pivotal to behavioral outcome. A low prednisolone dose antagonized methotrexate preventing deficits, whereas a higher prednisolone dose altered behavior by enhancing effects of methotrexate and radiation. These findings emphasize that steroids are important in agent interactions. Their role in morbidity associated with leukemia treatment protocols may be equally important as that of methotrexate and cranial irradiation. (Pediatr Res 35: 171-178, 1994)
\end{abstract}

\section{Abbreviations}

ALL, acute lymphoblastic leukemia $P$, prednisolone treatment

$M$, methotrexate treatment

$X, 1000$ cGy cranial irradiation

i.p., intraperitoneal

BI, behavioral initiations

BTT, behavioral total time

BTS, behavioral time structure

Received April 26, 1993; accepted September 27, 1993

Correspondence and reprint requests: Dr. Phyllis Mullenix, Department of Toxicology, Forsyth Research Institute, 140 Fenway, Boston. MA 02115. Supported by NIH CA53858.
Treatment of the CNS is a standard component of therapy for childhood ALL. Although the efficacy of CNS treatment is well documented (1), concerns remain about late-occurring neurotoxicity. The adverse effects, especially cognitive impairment, have been described extensively in clinical studies of children (2-5). The actual cause of these adverse effects, however, remains problematic. Treatment protocols for ALL typically involve multiple courses of systemic chemotherapy as well as CNS therapy. The latter usually involves intrathecal methotrexate, often alone or with intrathecal cytosine arabinoside and hydrocortisone, and sometimes with cranial irradiation and systemic steroids $(6,7)$. Some investigators have attributed neuropsychologic deficits primarily to cranial irradiation (8); others report that intrathecal methotrexate is equally neurotoxic (9). Still other investigators have suggested that it is the interaction of cranial irradiation and chemotherapy that is causal, and that the severity of neurotoxicity is directly proportional to the number of therapeutic modalities used $(10,11)$. Steroids are commonly given in combination with cranial irradiation and chemotherapy in treatment of leukemia, but they have not been considered as potentially toxic agents, despite their demonstrated effects in animals on neural development $(6,9,12,13)$.

Evaluation of neurotoxicity in the clinical context is usually undertaken on a retrospective basis because design of investigational protocols must be motivated primarily by consideration of efficacy. An animal model, however, allows for controlled prospective investigations. In previous studies, we demonstrated that a rat model provided a feasible approach to delineating the agents responsible for the neurotoxicity associated with CNS therapy (14, 15). Growth and behavioral effects of $1000 \mathrm{cGy}$ cranial irradiation $(\mathrm{X})$ were compared with those of $\mathrm{X}$ combined with $18 \mathrm{mg} / \mathrm{kg}$ prednisolone and $2 \mathrm{mg} / \mathrm{kg}$ methotrexate (PMX). Both $X$ and PMX significantly affected growth (15), but $X$ alone only minimally affected behavior. In contrast. PMX markedly disrupted behavior in male animals (14). The minimal behavioral effect of $X$ contradicts clinical studies implicating cranial irradiation as the primary agent of neurotoxicity. Also, the sex specificity of the PMX response indicates that the relationship of neurotoxicity with the number of therapeutic modalities is not a simple one of direct proportionality.

The present study used the same animal model to further explore the cause of behavioral deficits induced by CNS therapies (14, 15). We evaluated the effects of three therapeutic agents: steroid, methotrexate, and cranial irradiation. These agents were examined alone and in paired combinations so that dose-related interactions could be characterized as synergistic, additive, or antagonistic with respect to neurotoxicity. 


\section{MATERIALS AND METHODS}

Eight hundred ten pathogen-free Sprague-Dawley rats, $9 \mathrm{~d}$ old (day of birth $=0$ ), were obtained from the Charles River Laboratories (Kingston, RI). They were shipped with dams and housed $10 \mathrm{pups} / \mathrm{dam}$. Specified nonlittermates, each sex was assigned randomly to either an experimental group or its matched control. Certified Purina Rat Chow (5002, Ralston-Purina, St. Louis, MO) and tap water ad libitum were given to the rats except during the short behavioral observation periods. Light cycles were maintained as 12 -h light $(0600 \mathrm{~h}$ to $1800 \mathrm{~h}) /$ dark periods All pups were weaned on $\mathrm{d} 21$ and housed two per cage per sex. Individual body weight was recorded, but effects on growth are discussed in detail elsewhere (16). All procedures involving animals were conducted under the auspices of Forsyth's linstitutional Animal Care and Use Committee.

The therapy groups are shown in Table 1. Those involving steroid (prednisolone sodium succinate in saline: Sigma Chemical Co., St. Louis, MO) received an i.p. injection on postnatal d 17 and again on d 18 before methotrexate or radiation treatments. Therapy groups given methotrexate $[(+)$ amethopterin in saline; Sigma] received a single i.p. injection on d $18,1-3 \mathrm{~h}$ before radiation. The doses of steroid and methotrexate (Table 1) were selected to be clinically relevant and to avoid lethality or obvious neurotoxicity (15). Controls received sham i.p. injections of an equal volume of saline per body weight on d 17 and/or d 18 to match each experimental therapy (Table 1 ).

The therapy groups receiving cranial irradiation were exposed on $\mathrm{d} 18$ between 0900 and $1200 \mathrm{~h}$ using previously described procedures (15). Rats were immobilized with pentobarbital anesthesia $(25 \mathrm{mg} / \mathrm{kg}$, i.p.). They were exposed six to eight at a time to a lateral beam of $x$-rays produced by an $x$-ray machine operating at $250 \mathrm{kV}$ peaks with $0.35-\mathrm{mm}$ copper filtration. Each animal was shielded with $2 \mathrm{~mm}$ of lead placed over the body and face. The eyes, oropharyngeal mucosa, and salivary tissues were protected while the skull was exposed from behind the eyes to the midposterior neck. The calculated mid-brain dose rate was $125 \mathrm{cGy} / \mathrm{min}$; each irradiated brain received a total of 1000 $\mathrm{cGy} \pm 5 \%$ in a single fraction over $8 \mathrm{~min}$. This dose approximated a biologic equivalent to the clinical dose of $2400 \mathrm{cGy}$ given in 12-14 fractions (15). After pentobarbital anesthesia, control animals were sham irradiated by similar placement in the radiation beam but with complete shielding by $6 \mathrm{~mm}$ of lead.

Spontaneous behavior was analyzed in the rats at $6 \mathrm{wk}$ and 4 mo of age using the same methodology as in our previous study (14). All tests were conducted between 0900 and $1300 \mathrm{~h}$. Two video cameras taking one frame per second were used to monitor simultaneously the spontaneous behavior of one experimental rat and its matched control during a 15-min exploration of a novel environment. The video signals were transferred to a MICRO VAX I and a VAX 11/750 (Digital Equipment Corp., Maynard. MA) for pattern analysis and behavioral classification of the data. The behaviors identified by the computer consisted of five major body positions (stand, sit, rear, walk, and lying down) and eight modifiers (groom, head turn, look, smell, sniff. turn, wash face. and blank or no recognized activity). The overall system of cameras, computers. computer software, and novel environment has been described in detail (17).

Three measures of spontaneous behavior were made as in our previous study (14): a calculation of BI and BTT and a measure of BTS concerning the time distribution of the initiation of discrete acts and of sequences of joint acts.

Calculation of $B I$. The frames in which a specific behavior began were totaled for each act during the 15 -min observation period for each rat. The mean number of initiations per act was determined for each control and experimental group of rats. A $t$ test was applied. and a $p<0.05$ was required for statistical significance.

Calculation of BTT. The number of frames that a behavior continued, including the frame it was initiated, was totaled for the 15 -min observation period. The mean total time for each act in control and experimental groups of rats was determined, and statistical significance was evaluated using the $t$ test, with a $p<$ 0.05 required for a change to be considered significant.

(alculation of BTS. The time distribution and time sequence of behavioral acts were calculated using equations for $K(t)$ which have been described extensively $(18-21)$. For both sexes, the function $\mathrm{K}(\mathrm{t})$ was computed for 19 or 20 pairs per therapy group listed in Table 1, a pair consisting of one experimental animal and one matched control. The $\mathrm{K}$ function was calculated for specific behavioral acts (e.g. sit, rear) or sequences of specific behavioral acts (sit ... rear) (19) and for combined acts (e.g. attention or attention/groom) or sequences of combined acts (e.g. attention ... explore or attention/explore ... groom/attention) (18). For each of these, a $\triangle \mathrm{K}(\mathrm{t})$ [the difference between $\mathrm{K}(\mathrm{t})$ for the experimental animals and the matched controls] was calculated for eight time points $(2,5,10,20,30,45,100$, and $200 \mathrm{~s})$. At any one time point, when larger $\mathrm{K}$ values were found for one behavior over another, it meant that that particular behavior (or sequence) was more "clustered" in time and the other behavior was correspondingly more "dispersed" in time (it had increased time spacing between initiations). Whenever a behavioral act was initiated less than 10 times on average per animal, control or experimental, $K(t)$ values were not determined

\begin{tabular}{|c|c|c|c|c|c|}
\hline Therapy (abbreviation*) & Male & Female & Matched control & Male & Female \\
\hline Prednisolone. $18 \mathrm{mg} / \mathrm{kg}\left(\mathrm{P}_{18}\right)$ & 20 & 20 & $C-P_{1 \times}$ & 20 & 20 \\
\hline Prednisolone, $36 \mathrm{mg} / \mathrm{kg}\left(\mathrm{P}_{36}\right)$ & 20 & 19 & $\mathrm{C}-\mathrm{P}_{3 \mathrm{n}}$ & 19 & 20 \\
\hline Methotrexate, $2 \mathrm{mg} / \mathrm{kg}\left(\mathrm{M}_{2}\right)$ & 29 & 20 & $\mathrm{C}-\mathrm{M}_{2}$ & 21 & 29 \\
\hline Methotrexate. $4 \mathrm{mg} / \mathrm{kg}\left(\mathrm{M}_{4}\right)$ & 28 & 28 & $\mathrm{C}-\mathrm{M}_{4}$ & 25 & 24 \\
\hline $\begin{array}{l}\text { Prednisolone. } 18 \mathrm{mg} / \mathrm{kg}+ \\
\text { Methotrexate. } 2 \mathrm{mg} / \mathrm{kg}\left(\mathrm{P}_{18} \mathrm{M}_{2}\right)\end{array}$ & 23 & 23 & $C-P_{1 \times} M_{2}$ & 22 & 22 \\
\hline $\begin{array}{l}\text { Prednisolone, } 36 \mathrm{mg} / \mathrm{kg}+ \\
\text { Methotrexate, } 4 \mathrm{mg} / \mathrm{kg}\left(\mathrm{P}_{36} \mathrm{M}_{4}\right)\end{array}$ & 22 & 23 & $\mathrm{C}-\mathrm{P}_{3 n} \mathrm{M}_{4}$ & 22 & 22 \\
\hline $\begin{array}{l}\text { Methotrexate, } 2 \mathrm{mg} / \mathrm{kg}+ \\
\text { Cranial irradiation, } 1000 \mathrm{cGy}\left(\mathrm{M}_{2} \mathrm{X}\right)\end{array}$ & 25 & 21 & $\mathrm{C}-\mathrm{M}_{2} \mathrm{X}$ & 21 & 24 \\
\hline $\begin{array}{l}\text { Methotrexate. } 4 \mathrm{mg} / \mathrm{kg}+ \\
\text { Cranial irradiation, } 1000 \mathrm{cGy}\left(\mathrm{M}_{4} \mathrm{X}\right)\end{array}$ & 21 & 23 & $C-M_{4} X$ & 21 & 23 \\
\hline $\begin{array}{l}\text { Prednisolone, } 18 \mathrm{mg} / \mathrm{kg}+ \\
\text { Cranial irradiation, } 1000 \mathrm{cGy}\left(\mathrm{P}_{1 \times} \mathrm{X}\right)\end{array}$ & 23 & 22 & $C-P_{1 \times} X$ & 22 & 23 \\
\hline
\end{tabular}


for that behavior and related sequences. The bootstrap technique was used for estimating SD at each time point of the $\mathrm{K}$ function for a behavior, and the ad hoc criteria for significance of a difference between control and exposed groups were the same as in the study of PMX and X therapies (14).

The ad hoc RS statistic was developed to distinguish low level behavioral effects from noise (22). The RS encompasses all data produced in an experiment in one simple statistic. This is an advantage considering that the computer system generates over 100 behavioral measures of three distinctly different types (initiations, total times, and time structures) per experiment. The RS statistic indicates whether behavior is changed overall and the confidence level associated with that change. An RS statistic was determined for each therapy group in Table 1 and for the PMX and X therapies described in our previous study (14). Statistical significance was set at the $p<0.01$ level.

\section{RESULTS}

Figure 1 illustrates the behavioral effects of each therapy in 6wk-old animals and highlights the influence of dose, sex, and agent interactions on overall behavioral change. This screening information revealed the following characteristics of CNS therapies.

The cause of effects on behavior: combinations. Behavior was affected by more combined-agent therapies than single-agent therapies (Fig. 1). The three-agent combination $P_{18} M_{2} X$ in males induced the most dramatic effect upon behavior, and the twoagent combinations usually altered behavior to a greater extent than the single agents. The only single agent that affected behavior was $\mathrm{P}_{18}$, and this effect occurred only in males. The data are not presented here, but we found that the steroid dexamethasone $(1 \mathrm{mg} / \mathrm{kg}$, i.p. on day 18$)$ also affected behavior in males only (RS statistic at $6 \mathrm{wk}$ of age $=0.279, p<0.001$ ). Single therapies $\mathrm{M}_{2}$ and $\mathrm{X}$ tended to affect behavior in females, although the effects were not statistically significant at any age.

Sex-influenced effects on behavior. Behavioral response to each therapy was usually sex dependent (Fig. 1). Females often exhibited behavioral effects at lower doses of combined therapies than males. For example, the $\mathrm{M}_{2} \mathrm{X}$ combination, which did not affect behavior of males, significantly altered behavior in females. $\mathrm{P}_{36} \mathrm{M}_{4}$ also affected only females. In contrast, males were affected more by the three-agent combinations, both $P_{18} M_{2} X$ and $P_{36} M_{4} X$ $\left(\mathrm{P}_{36} \mathrm{M}_{4} \mathrm{X}\right.$ data not shown). Figure 2 illustrates the sex dependency

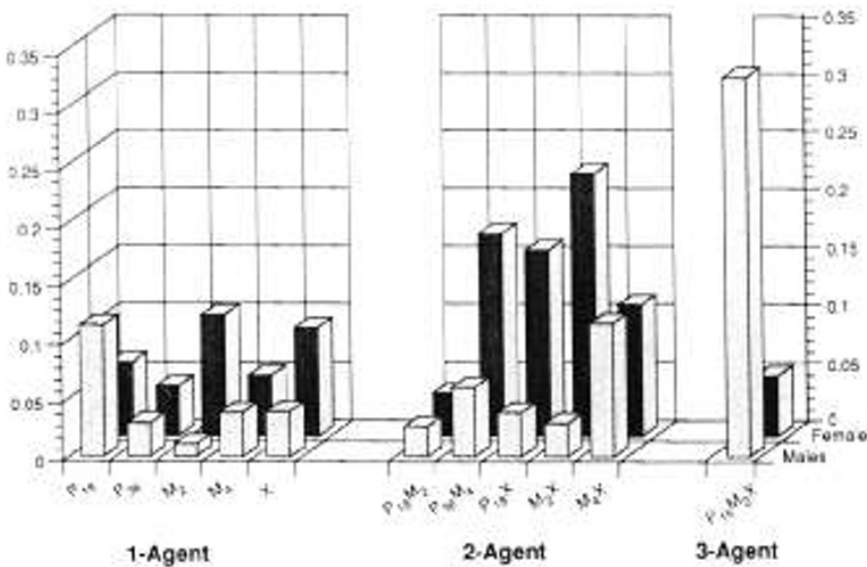

Fig. 1. The overall effects of one-, two-, and three-agent combinations on behavior in 6-wk-old male and female rats. Each bar represents the RS statistic per therapy compared with matched controls. For females. the therapies having significant alteration in the RS statistic are the following: $\mathrm{P}_{36} \mathrm{M}_{4}(\mathrm{RS}=0.181, p<0.001) ; \mathrm{M}_{2} \mathrm{X}(\mathrm{RS}=0.226, p<0.001)$ : $\mathrm{M}_{4} \mathrm{X}(\mathrm{RS}=0.113, p<0.01)$ : and $\mathrm{P}_{18} \mathrm{X}(\mathrm{RS}=0.160, p<0.001)$. For males, the therapies having significant alteration in the RS statistic are the following: $\mathrm{P}_{18}(\mathrm{RS}=0.113, p<0.01): \mathrm{M}_{4} \mathrm{X}(\mathrm{RS}=0.115, p<0.01)$; and $P_{18} M_{2} X[R S=0.328$, Mullenix $e t$ al. (14)].
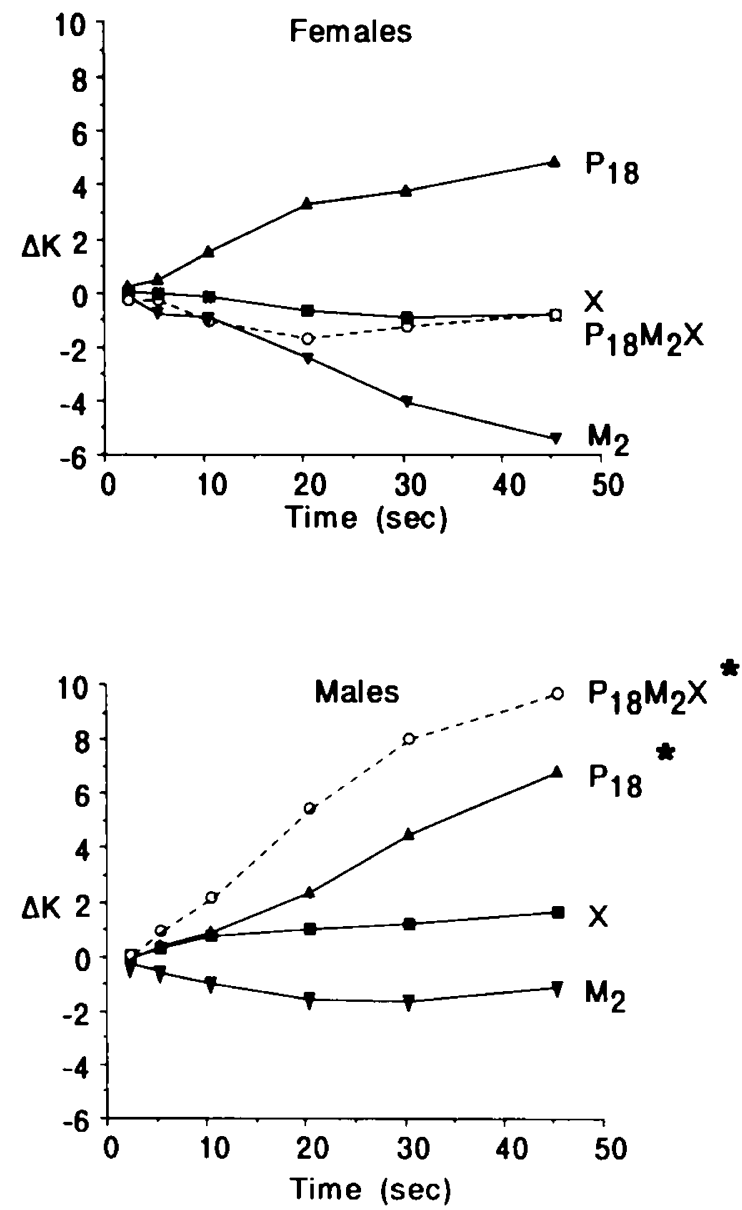

Fig. 2. Sex-dependent effects of a three-agent combination in 6-wkold rats. Synergism among components of the $P_{18} M_{2} X$ combination resulted in behavioral alteration in males. $P_{18} M_{2} X$. similar to $P_{18}$ only to a greater extent, dispersed (positive $J K$ values) time structure of this behavioral sequence in males. In contrast, antagonism among the components of this combination dominated in females, resulting in no behavioral alteration in that sex. $\Delta K(t)$ [the difference between $K(t)$ for a control and an exposed group] at the first six time points evaluated are for the combined act sequences attention/groom ... attention/explore in females and explore . . attention/groom in males. The $\triangle \mathrm{Ks}$ for $\mathrm{P}_{18}$ $(\boldsymbol{\Delta}), \mathrm{M}_{2}(\boldsymbol{\nabla}), \mathrm{X}(\boldsymbol{\square})$, and $\mathrm{P}_{18} \mathrm{M}_{2} \mathrm{X}(-\mathrm{O}-)$ are compared. Asterisks denote significant difference from matched controls.

in response to $P_{18} M_{2} X$; the three agents interacted producing essentially no behavioral effect in females but a dramatic behavioral effect in males. Virtually every male behavior altered by $\mathrm{P}_{18} \mathrm{M}_{2} \mathrm{X}$ in our earlier study (14) was similarly affected (although not necessarily to the same extent) by $P_{18}$ alone. In short, the $P_{18}$ effect in males was the best predictor of effects induced by the combination of $\mathrm{P}_{18} \mathrm{M}_{2} \mathrm{X}$ in that sex. In males, therefore, the $\mathrm{P}_{18}$ effect was dominant.

Both males and females were affected by certain combination therapies. Both sexes were affected by $M_{4} X$ and $P_{18} X$. Although Figure 1 shows that behavior was altered significantly in 6-wkold $P_{18} X$ females but not males, changes emerged for $P_{18} X$ males as well by $4 \mathrm{mo}$ of age (RS statistic $=0.151, p<0.001)$. With both sexes showing significant changes in response to $P_{18} X$ and $\mathrm{M}_{4} \mathrm{X}$, these combinations appeared to be among the more potent for affecting behavior.

Behavioral effects specific to combinations. The behavioral deficits induced by combination therapies depended upon the combination's components. A combination including prednisolone and methotrexate in females primarily affected BI and BTT (12 significant BI and BTT changes compared with four significant BTS changes), whereas radiation coupled with either meth- 
otrexate or prednisolone affected BTS (significant BI and BTT changes never exceeded two). The statistically significant alterations in $\mathrm{BI}$ and $\mathrm{BTT}$ by $\mathrm{P}_{36} \mathrm{M}_{4}$ in 6-wk-old females are listed in Table 2. Figure 3 illustrates that MX combinations affecting BTS characteristically dispersed behaviors at $6 \mathrm{wk}$ of age, $i$. time structure was dispersed in nine of 11 behaviors altered in $\mathrm{M}_{4} \mathrm{X}$ females. In contrast, PX combinations affecting BTS characteristically clustered most behaviors at $6 \mathrm{wk}$, i.e. $\mathrm{P}_{18} \mathrm{X}$ clustered 11 of 13 behaviors altered in time structure in 6-wk-old females.

Outcome of agent interactions: antagonism or synergism. Behavioral outcome was highly dependent upon interactions of agents in a combination therapy. Some agent combinations interacted antagonistically, which led to protection or mitigation of behavioral effects caused by each agent alone. Behavior was not affected by $P_{18} M_{2}$ in either sex or by $M_{2} X$ in males (Fig. 1). Figure 4 illustrates the protective antagonism by $\mathrm{P}_{18} \mathrm{M}_{2} \mathrm{P}_{18}$ consistently altered BTS in a way opposite from $\mathbf{M}_{2}$. As a consequence, the two agents in combination acted to compensate for one another, so that the $\mathrm{P}_{18} \mathrm{M}_{2}$ combination did not significantly alter behavior in either sex. The protective antagonism between $M_{2}$ and $X$ in males is shown in Table 3 . The effects of $X$ on BI and BTT were mitigated when $\mathrm{M}_{2}$ and $X$ were combined $\left(M_{2} X\right)$. Such protective antagonism between $M_{2}$ and $X$ was not evident in females, who instead displayed enhanced neurotoxicity via synergism when exposed to $M_{2} X$.

Table 2. Significant BI and BTT changes by $P_{36} M_{4}$ in 6-wk-old female rats

\begin{tabular}{lcc}
\hline \multicolumn{1}{c}{ Behavior } & Control & $\mathrm{P}_{36} \mathrm{M}_{4}$ \\
\hline $\mathrm{BI}^{*}$ & & \\
Specific & $25.5 \pm 2.6$ & $38.2 \pm 2.6 \dagger$ \\
$\quad$ Sit & $11.1 \pm 1.5$ & $18.1 \pm 1.9 \dagger$ \\
Groom & $0.9 \pm 0.3$ & $3.0 \pm 0.6 \dagger$ \\
$\quad$ Wash face & & \\
Combined & $9.1 \pm 1.4$ & $16.8 \pm 1.8 \dagger$ \\
$\quad$ Groom & $26.2 \pm 3.4$ & $35.8 \pm 2.9 \ddagger$ \\
$\quad$ Groom/attention & & \\
BTT§ & & \\
Specific & $66.8 \pm 11.2$ & $104.4 \pm 11.7 \ddagger$ \\
Sit & $16.9 \pm 2.7$ & $33.3 \pm 4.6 \dagger$ \\
$\quad$ Groom & $1.1 \pm 0.4$ & $3.9 \pm 0.8 \dagger$ \\
Wash Face & $529.7 \pm 15.7$ & $471.6 \pm 13.2 \dagger$ \\
Stand & $45.3 \pm 3.0$ & $37.5 \pm 2.2 \ddagger$ \\
$\quad$ Look & & \\
Combined & $13.9 \pm 2.3$ & $28.9 \pm 4.0 \dagger$ \\
$\quad$ Groom & $435.8 \pm 14.5$ & $379.0 \pm 13.7 \dagger$ \\
$\quad$ Attention & & \\
\hline
\end{tabular}

* Average initiations \pm SEM.

$+p<0.01 ; t$ test.

$\ddagger p<0.05 ; t$ test.

$\S$ Average seconds \pm SEM.
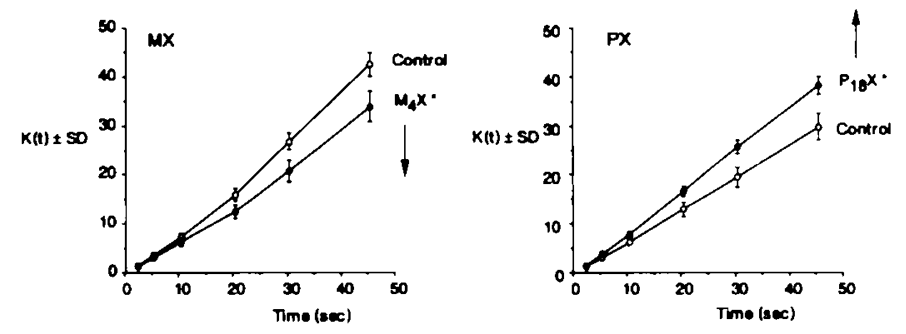

Fig. 3. Behavioral "signatures" in time structures by $M X$ and $P X$ combinations $(\Theta)$ compared with respective controls $(O)$. This example shows $\mathbf{M}_{4} \mathrm{X}$ dispersion of the sequence explore ... groom (decreased $\mathrm{K}$ values) and $P_{18} X$ clustering of the sequence groom ... attention/explore (increased $\mathrm{K}$ values). $\mathrm{K}$ functions are for behavioral time sequences in 6-wk-old female rats. Error bars indicate \pm SD, and asterisks denote significant difference from matched controls.
The agent combinations that interacted synergistically led to effects greater than expected from either agent alone. Table 4 demonstrates synergistic interaction by the $P_{36} \mathrm{M}_{4}$ combination using BI and BTT measures. The combination effect of $\mathrm{P}_{36} \mathrm{M}_{4}$ was greater than the effects of either $P_{36}$ or $M_{4}$ alone, and it clearly was not a result of an additive reaction. The BTS measure also revealed synergisms, such as the response to $\mathrm{M}_{4} \mathrm{X}$ in males and females shown in Figure 5. The sum of the effects of $\mathbf{M}_{4}$ alone and $\mathrm{X}$ alone did not equal the effects of $\mathrm{M}_{4} \mathrm{X}$; rather, the combination effect was greater than expected from either agent alone. In fact, $\mathrm{M}_{4} \mathrm{X}$ in 6-wk-old females, for example, affected 11 different behaviors and sequences, nine of which were not affected by either $\mathrm{M}_{4}$ alone or $\mathrm{X}$ alone.

Dose-affected outcome. Dose appeared to determine the outcome of agent interactions. Low-dose interactions could result in antagonism, and high-dose interactions in synergism. Figure 6 demonstrates dose-dependent conversion of antagonism to synergism for MX and PM combinations using the BTS measure. Because only one PX combination was examined, its dose dependency could not be determined. Additional dose-response studies are under way to expand these initial observations.

\section{DISCUSSION}

Behavioral deficits resulted primarily from combined agent therapies, consistent with findings of other studies in humans $(10,11)$ and animals $(23)$. No single agent was the sole source of neurotoxicity. The components of these combinations interacted synergistically, not additively, to affect behavior. The combined effect $\left(M_{2} X, M_{4} X, P_{18} X, P_{36} M_{4}\right)$ was greater than the sum of the effects of each component given alone (X, $M_{2}, M_{4}, P_{18}$, or $\left.P_{36}\right)$. The components, however, dictated the behavioral "signatures" found in the 6-wk-old rats. For example, a prednisolone and methotrexate combination increased the initiations and lengthened the durations of certain sedentary behaviors (sit, groom. and wash face) as in hypoactivity (24). A methotrexate and radiation combination dispersed BTS as in amphetamine hyperactivity (25), whereas a prednisolone and radiation combination clustered time structure similar to the neurotoxin triethyltin (24). A combination of all three agents clustered some BTS while dispersing others (14).

Among the combinations, however, one single agent, prednisolone, was pivotal to behavioral outcome by interacting with cranial irradiation and methotrexate. Depending upon the dose, prednisolone either antagonized methotrexate $\left(\mathrm{P}_{18} \mathrm{M}_{2}\right)$, resulting in protection from effects on behavior, or enhanced methotrexate and radiation effects $\left(\mathrm{P}_{36} \mathrm{M}_{4}, \mathrm{P}_{18} \mathrm{X}\right)$ and thus altered behavior. Other studies of CNS injury have shown that the effects of glucocorticoid steroids on neuronal viability also change from protective to deleterious depending upon dose, duration of treatment, and the steroid's chemical structure $(26,27)$.

Prednisolone clearly potentiated the effects of methotrexate and radiation in the three-agent combination $P_{18} M_{2} X$. In males, exaggerated behavioral effects by $\mathrm{P}_{18} \mathrm{M}_{2} \mathrm{X}$ contrasted the smaller effects by $P_{18}$ and the lack of effect by $M_{2} X$. This prednisolone potentiation of radiation and methotrexate, the latter a wellknown antimetabolite (28), may be similar to other steroidantimetabolite interactions reported in the literature. Glucocorticoid steroids are known to potentiate hippocampal damage from metabolic insults by various neurotoxins (29) and ischemic injury (30) in rats. In turn, hippocampal damage is frequently linked with memory and learning deficits (31). Children who survive leukemia, whose treatment typically includes prolonged prednisone therapy, exhibit memory deficits $(9,32,33)$, as do children treated with prednisone for asthma $(34,35)$. Alone. methotrexate alters development of synapses in the hippocampus of the neonatal rat (36), and prolonged glucocorticoid exposure reduces hippocampal neuron number, thus contributing to the aging process and its associated memory deficits in rats $(37,38)$. Because the hippocampus was still developing (39) at the age rats 
Antagonism
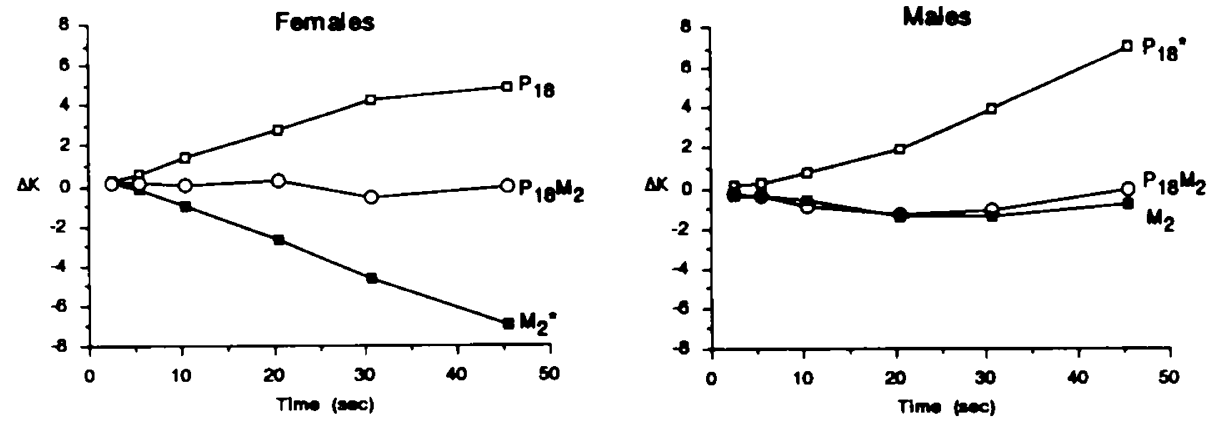

Fig. 4. Prednisolone and methotrexate antagonism using a measure of BTS. $P_{18}$ alone dispersed this behavioral sequence (positive $\lrcorner K$ values). and $M_{2}$ alone clustered it (negative $J K$ values) in both sexes. When $P_{1 x}$ and $M_{2}$ were combined, the $P_{1 x} M_{2}$ combination produced $K$ values near those of matched controls. $J K(t)$ [the difference between $K(t)$ for a control and an exposed group] at the first six time points evaluated is shown. The $\Delta \mathrm{Ks}$ for $\mathrm{P}_{18}(\square), \mathrm{M}_{2}(\mathbf{D})$, and $\mathrm{P}_{18} \mathrm{M}_{2}(\mathrm{O})$ are compared for the combined act sequence attention/groom ... explore in 6-wk-old males and females. Asterisks denote significant difference from matched controls.

Table 3. Antagonism between methotrexate and radiation in male rats

\begin{tabular}{|c|c|c|c|c|c|c|}
\hline Measure & Behavior* & Age & Controlst & $x$ & $\mathrm{M}_{2}$ & $M_{2} X$ \\
\hline \multirow[t]{4}{*}{$\mathrm{Bl}( \pm \mathrm{SEM})$} & Sit & $6 \mathrm{wk}$ & $27.7 \pm 3.9$ & $17.1 \pm 1.6 \ddagger$ & $28.5 \pm 3.6$ & $28.4 \pm 2.9$ \\
\hline & Sit & $4 \mathrm{mo}$ & $43.8 \pm 6.1$ & $31.8 \pm 3.0 \$$ & $50.4 \pm 4.4$ & $42.8 \pm 3.6$ \\
\hline & GR/ATT & $6 \mathrm{wk}$ & $30.4 \pm 4.3$ & $19.1 \pm 2.6 \$$ & $31.0 \pm 4.1$ & $31.1 \pm 3.3$ \\
\hline & GR/EXP & $4 \mathrm{mo}$ & $24.7 \pm 3.6$ & $15.6 \pm 1.9 \ddagger$ & $28.3 \pm 3.5$ & $22.4 \pm 2.3$ \\
\hline \multirow[t]{2}{*}{ BTT ( \pm SEM) } & Sit & $4 \mathrm{mo}$ & $140.6 \pm 20.8$ & $82.8 \pm 9.4 \$$ & $169.3 \pm 21.6$ & $163.3 \pm 22.8$ \\
\hline & GR/EXP & $4 \mathrm{mo}$ & $32.6 \pm 4.9$ & $21.1 \pm 2.6 \$$ & $37.8 \pm 5.0$ & $29.1 \pm 3.2$ \\
\hline
\end{tabular}

* GR, combined act groom; ATT, combined act attention; EXP. combined act explore.

+ Pooled controls (C-X, C-M,$\left.C-M_{2} X\right)$.

$\ddagger p<0.01$ compared with $\mathrm{C}-\mathrm{X}: t$ test.

$\S p<0.05$ compared with $\mathrm{C}-\mathrm{X}: t$ test.

Table 4. Synergism between prednisolone and methotrexate in 6-nk-old female rats

\begin{tabular}{|c|c|c|c|c|c|}
\hline Measure & Behavior* & Controlst & $\mathrm{P}_{36}$ & $\mathrm{M}_{4}$ & $\mathrm{P}_{30} \mathrm{M}_{4}$ \\
\hline \multirow[t]{5}{*}{$\mathrm{BI}( \pm \mathrm{SEM})$} & Sit & $22.3 \pm 3.2$ & $24.9 \pm 2.2$ & $15.4 \pm 1.5$ & $38.2 \pm 2.67$ \\
\hline & Groom & $10.2 \pm 1.6$ & $12.1 \pm 2.1$ & $8.8 \pm 1.7$ & $18.1 \pm 1.9 \ddagger$ \\
\hline & Wash face & $0.8 \pm 0.1$ & $1.3 \pm 0.4$ & $0.8 \pm 0.2$ & $3.0 \pm 0.6 \ddagger$ \\
\hline & GR & $8.4 \pm 1.3$ & $11.0 \pm 2.1$ & $7.3 \pm 1.5$ & $16.8 \pm 1.8 \ddagger$ \\
\hline & GR/ATT & $21.9 \pm 3.2$ & $26.6 \pm 3.0$ & $12.7 \pm 1.6$ & $35.8 \pm 2.9 \$$ \\
\hline \multirow[t]{7}{*}{ BTT $( \pm$ SEM $)$} & Sit & $61.3 \pm 9.9$ & $75.6 \pm 12.7$ & $35.5 \pm 5.4$ & $104.4 \pm 11.7$ \\
\hline & Groom & $17.6 \pm 3.1$ & $23.5 \pm 5.5$ & $13.4 \pm 2.7$ & $33.3 \pm 4.6 \neq$ \\
\hline & Wash face & $1.4 \pm 0.4$ & $1.5 \pm 0.4$ & $1.0 \pm 0.3$ & $3.9 \pm 0.8 \ddagger$ \\
\hline & Stand & $529.1 \pm 69.8$ & $517.9 \pm 12.8$ & $525.5 \pm 11.9$ & $471.6 \pm 13.2$ \\
\hline & Look & $38.9 \pm 5.3$ & $33.9 \pm 3.2$ & $37.3 \pm 2.1$ & $37.5 \pm 2.28$ \\
\hline & GR & $14.2 \pm 2.5$ & $19.4 \pm 4.6$ & $10.4 \pm 2.0$ & $28.9 \pm 4.0 \ddagger$ \\
\hline & ATT & $430.2 \pm 56.8$ & $413.1 \pm 12.8$ & $436.0 \pm 11.4$ & $379.0 \pm 13.7 \ddagger$ \\
\hline
\end{tabular}

* GR, combined act groom; ATT. combined act attention.

+ Pooled controls $\left(C-\mathrm{P}_{36}, \mathrm{C} \cdot \mathrm{M}_{4}, \mathrm{C}-\mathrm{P}_{36} \mathrm{M}_{4}\right)$.

$\ddagger p<0.01$ compared with $C-\mathrm{P}_{36} \mathrm{M}_{4}: t$ test.

$\S p<0.05$ compared with C. $\mathrm{P}_{36} \mathrm{M}_{4} ; t$ test.

were exposed here, alterations in hippocampal development may be important to consider in future studies of the potentiating effects of prednisolone.

Given the links between steroids, antimetabolites, hippocampal damage, and memory deficits in the literature and the prednisolone interactions observed here, steroids assume a greater significance in this context. Steroids are used during remission induction of ALL $(40,41)$ and sometimes during CNS prophylactic therapy to reduce the somnolence syndrome (7). Synergism between methotrexate and cranial irradiation has driven attempts to prevent neurotoxicity, usually by excluding the latter from CNS therapy $(9-11,42)$. Apparently, however, synergisms involving steroids deserve equal attention when morbidity associated with leukemia treatment protocols is evaluated. This is especially important in an era when clinicians are replacing radiation with intrathecal methotrexate combined with cytosine arabinoside and hydrocortisone (intrathecal triple therapy).

Behavioral outcome subsequent to combination therapies was often sex dependent. Only females were affected by $M_{2} X$, but both sexes were affected by $M_{4} X$. Therefore, with some combinations, the sex difference appeared to be a function of dose. The distinct prednisolone sensitivity of males, however, indicated that other factors can be involved, i.e. variations in susceptibility due to differences in the timing of brain development. There is a sexual dimorphism in rat hepatic steroid metabolism that correlates with sexual dimorphism in growth hormone secretion (43). Sexual dimorphism in growth hormone secretion in turn subserves gender differences in hypothalamic somatostatin and growth hormone-releasing hormone gene expression or mode of signaling to pituitary somatotropes $(44,45)$. All these sexual 


\section{Synergism}
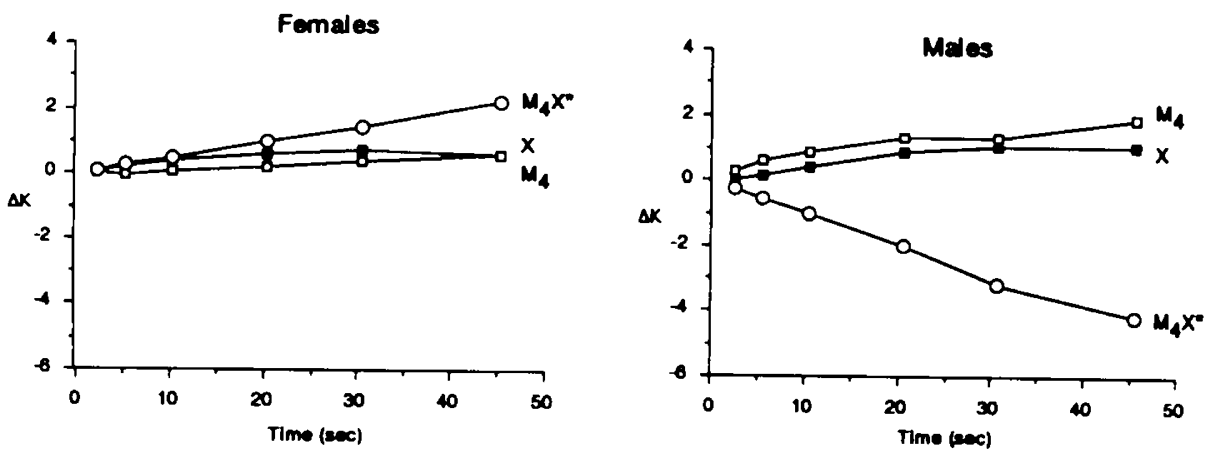

Fig. 5. Example of synergism using a measure of BTS. $\Delta K(t)$ [the difference between $K(t)$ for a control and an exposed group] at the first six time points evaluated is shown for representative behaviors in both sexes. The $\Delta \mathrm{Ks}$ for $\mathrm{X}(\boldsymbol{\square}), \mathrm{M}_{4}(\square)$, and $\mathrm{M}_{4} \mathrm{X}(\mathrm{O})$ are compared for the specific act sequence smell ... turn in 6-wk-old animals. Asterisks denote significant difference from matched controls.

\section{Antagonism $\longrightarrow$ Synergism}

Methotrexate and Radiation in Males
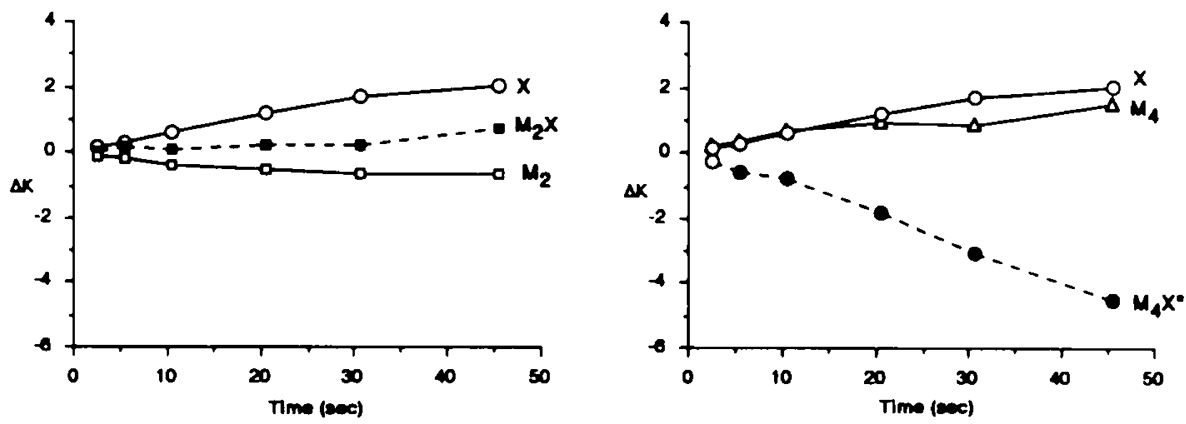

Prednisolone and Methotrexate in Females
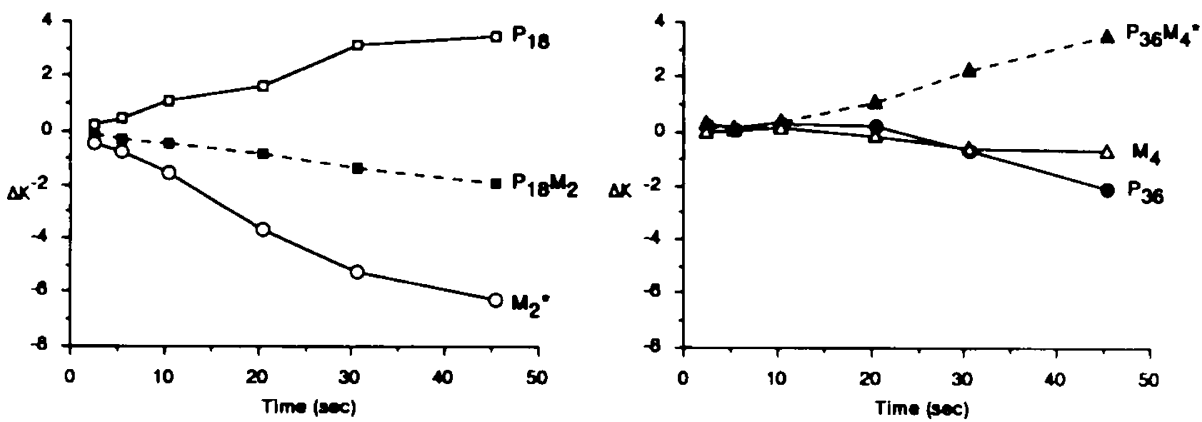

Fig. 6. Antagonism is replaced by synergism as dose of prednisolone, methotrexate, or both doubles within a combination. $\Delta K(t)$ [the difference between $\mathrm{K}(\mathrm{t})$ for a control and an exposed group] at the first six time points evaluated are for two representative behaviors in 6-wk-old rats. In the example for males, the $\Delta K s$ are $X(O), M_{2}(\square), M_{4}(\Delta), M_{2} X(-)$, and $M_{4} X\left(-\bullet_{-}\right)$for the specific act sequence turn ... smell. In the example for females, the $\Delta K s$ are $P_{18}(\square), P_{36}(\bullet), M_{2}(O), M_{4}(\Delta), P_{18} M_{2}(-)$, and $P_{36} M_{4}(-\Delta-)$ for the specific act sequence sit ... walk. Asterisks denote significant difference from matched controls.

dimorphisms are developmentally regulated, and that in the hypothalamus (44) is developing at about the age when animals were exposed in this study. Consequently, the involvement of combination therapies with sex-specific brain development, especially in the hypothalamus, is worth investigation, considering that sex sometimes determined whether or not outcome included neurotoxicity.

Antagonism between components of a combination is especially intriguing because of implications regarding antidotes. Behavioral effects of $P_{18}$ or $M_{2}$ alone did not occur with the $P_{18} M_{2}$ combination. Regardless of sex, $P_{18}$ usually affected BTS in an opposite direction from $\mathrm{M}_{2}$, resulting in a functional or physiologic antagonism in which two chemicals had opposing effects on the same physiologic function. When $M_{2}$ preceded $X$ in males, the two agents also interacted antagonistically, eliminating behavioral effects as well as reducing effects on growth (16). As yet we have not observed antagonism between methotrexate and radiation in females, but other dose combinations need to be studied before drawing conclusions about protection by preirradiation methotrexate. Geyer et al. (46) reported that methotrexate before radiation partially protected against white matter radionecrosis and forelimb paralysis in rats. Others have suggested that preirradiation methotrexate may help prevent CNS radiotoxicity in children and that it may benefit girls more 
than boys (47). More dose-response studies are needed to determine whether adjustment of dose per agent within a combination accomplishes antagonisms that protect against CNS therapy effects on growth and behavior. If such protective titration is possible, the clinical use of maximally tolerated doses should be reconsidered.

Children treated for leukemia are usually not treated with combinations as simple as the MX. PM, and PX combinations studied here. Throughout the course of treatment, they receive combinations of many drugs (including vincristine, 6-mercaptopurine, asparaginase, and an anthracycline), providing abundant opportunity for unexpected interactions. These complex combinations, and the varied time course of their administration, hinder clear-cut correlations between clinical findings and experimental results presented here. Nonetheless, there are similarities. As in our study, in children treated for leukemia, behavioral deficits are more prevalent in females in some series of protocols $(5,32,48)$. Waber et al. (32) also found that the expression of neurotoxicity can be sex dependent with one therapy and not another, suggesting involvement of two different mechanisms. The sex-dependent therapy included methotrexate; females but not males were sensitive and lower IQ was the outcome. The non-sex-related therapy included cranial irradiation, glucocorticoid steroid, asparaginase, and doxorubicin; both sexes exhibited deficits in a specific set of cognitive processes involving verbal coding and/or memory. Findings from the present study were similar: female animals were more sensitive than males to therapies involving methotrexate; there were therapies that affected both sexes at the same dose level; and neurotoxic outcome varied with the therapy. The effects of prednisolone in the present study were striking and are of major clinical importance. We are currently evaluating dose-response relationships for glucocorticoids in newly diagnosed children with ALL. If a low dose of steroid has equivalent leukemia cell cytotoxicity, we would consider the use of the lower dose in future trials and evaluate for subsequent neurotoxicity. Further comparison of clinical and experimental findings is important, because the neurotoxicity of CNS therapy for ALL might be decreased if optimal combinations of agents were understood.

\section{REFERENCES}

1. Inati A, Sallan SE, Cassady JR 1983 Efficacy and morbidity of central nervous system "prophylaxis" in childhood acute lymphoblastic leukemia: eight years' experience with cranial irradiation and intrathecal methotrexate. Blood 6:297-303

2. Meadows AT, Gordon J, Massari DJ. Littman P. Fergusson J. Moss K 1981 Decline in IQ scores and cognitive dysfunction in children with acute lymphocytic leukemia treated with cranial irradiation. Lancet $2 \cdot 1015-1018$

3. Moss HA, Nannis ED. Poplack DG 1981 The effects of prophylactic treatment of the central nervous system on the intellectual functioning of children with acute lymphocytic leukemia. Am J Med 71:47-52

4. Brouwers P, Riccardi R, Fedio P, Poplack DG 1985 Long-term neuropsychologic sequelae of childhood leukemia: correlation with $C T$ brain scan abnormalities. J Pediatr 106:723-728

5. Waber DP, Urion DK. Tarbell NJ, Sollee ND, Dinklage D, Gioia G, Paccia J, Sherman B. Niemeyer C. Gelber R. Sallan SE 1990 Late effects of central nervous system treatment of childhood acute lymphoblastic leukemia are sex-dependent. Dev Med Child Neurol 32:238-248

6. Bleyer WA. Poplack DG 1985 Prophylaxis and treatment of leukemia in the central nervous system and other sanctuaries. Semin Oncol 12:131-148

7. Mandell LR, Walker RW. Steinherz P. Fuks P 1989 Reduced incidence of the somnolence syndrome in leukemic children with steroid coverage during prophylactic cranial radiation therapy. Cancer 63:1975-1978

8. Dowell RE, Copeland DR, Francis DJ, Fletcher JM. Stovall M 1991 Absence of synergistic effects of CNS treatments on neuropsychologic test performance among children. J Clin Oncol 9:1029-1036

9. Mulhern RK. Wasserman AL. Fairclough D, Ochs J 1988 Memory function in disease-free survivors of childhood acute lymphocytic leukemia given CNS prophylaxis with or without $1.800 \mathrm{CGy}$ cranial irradiation. J Clin Oncol 6:315-320

10. Bleyer WA 1988 Central nervous system leukemia. Pediatr Clin North Am 35:789-814

11. Bleyer WA 1981 Neurologic sequelae of methotrexate and ionizing radiation a new classification. Cancer Treat Rep 65(Suppl 1):89-98

12. Uno H. Lohmiller L. Thieme C. Kemnitz JW. Engle MJ, Roecker EB. Farrell PM 1990 Brain damage induced by prenatal exposure to dexamethasone in fetal rhesus macaques. I. Hippocampus. Dev Brain Res 53:157-167
13. Benesova O. Pavlik A 1989 Perinatal treatment with glucocorticoids and the risk of maldevelopment of the brain. Neuropharmacology 28:89-97

14. Mullenix PJ, Kernan WJ. Tassinari MS. Schunior A. Waber DP. Howes A. Tarbell NJ 1990 An animal model to study toxicity of central nervous system therapy for childhood acute lymphoblastic leukemia: effects on behavior. Cancer Res 50:6461-6465

15. Schunior A. Zengel AE, Mullenix PJ. Tarbell NJ. Howes A. Tassinari MS 1990 An animal model to study toxicity of central nervous system therapy for childhood acute lymphoblastic leukemia: effects on growth and craniofacial proportion. Cancer Res 50:6455-6460

16. Schunior A. Mullenix PJ, Landy H, Zengel AE. Howes A. Tarbell NJ 1994 Radiation effects on growth are altered in rats by prednisolone and methotrexate. Pediatr Res (in press)

17. Kernan Jr WJ. Mullenix PJ, Hopper DL 1987 Pattern recognition of rat behavior. Pharmacol Biochem Behav 27:559-564

18. Kernan Jr WJ. Mullenix PJ, Kent R. Hopper DL. Cressie NA 1988 Analysis of the time distribution and time sequence of behavioral acts. Intern J Neurosci 43:35-51

19. Mullenix PJ. Kernan Jr WJ 1989 Extension of the analysis of the time structure of behavioral acts. Intern J Neurosci 44:251-262

20. Kernan Jr WJ. Mullenix PJ. Hopper DL 1989 Time structure analysis of behavioral acts using a computer pattern recognition system. Pharmacol Biochem Behav 34:863-869

21. Kernan WJ. Mullenix PJ 1991 Stability and reproducibility of time structure in spontaneous behavior in male rats. Pharmacol Biochem Behav 39:747754

22. Kernan WJ. Meeker WQ 1992 A statistical test to assess changes in spontaneous behavior of rats observed with a computer pattern recognition system. J Biopharm Stat 2:115-135

23. Yadin E. Bruno L. Micalizzi M. Rorke L. DAAngio G 1983 An animal model to detect learning deficits following treatment of the immature brain. Childs Brain 10:273-280

24. Kernan WJ. Hopper DL. Bowes MP 1991 Computer pattern recognition spontaneous motor activity studies of rats following acute exposure to triethyltin. J Am Coll Toxicol 10:705-718

25. Mullenix PJ, Kernan Jr WJ. Tassinari MS. Schunior A 1989 Generation of dose-response data using activity measures. J Am Coll Toxicol 8:185-197

26. Hall EH 1990 Steroids and neuronal destruction or stabilization. Ciba Found Symp 153:206-214

27. Hall ED 1992 The neuroprotective pharmacology of methylprednisolone. J Neurosurg 76:13-22

28. Goldman ID 1977 Effects of methotrexate on cellular metabolism: some critical elements in the drug-cell interaction. Cancer Treat Rep 61:549-558

29. Sapolsky RM 1985 A mechanism for glucocorticoid toxicity in the hippocam pus: increased neuronal vulnerability to metabolic insults. J Neurosci 5:1228-1232

30. Sapolsky RM, Pulsinelli WA 1985 Glucocorticoids potentiate ischemic injur in neurons: therapeutic implications. Science 229:1397-1400

31. Altman J 1987 Morphological and behavioral markers of environmentally induced retardation of brain development. Environ Health Perspect 74:153168

32. Waber DP. Tarbell NJ, Kahn CM. Gelber RD, Sallan SE 1992 The relationship of sex and treatment modality to neuropsychological outcome in childhood acute lymphoblastic leukemia. J Clin Oncol 10:810-817

33. Ochs J, Mulhern RK 1988 Late effects of antileukemic treatment. Pediatr Clin North Am 35:815-833

34. Bender BG, Lerner JA. Poland JE 1991 Association between corticosteroids and psychologic change in hospitalized asthmatic children. Ann Allergy 66:414-419

35. Bender BG. Lerner JA, Kollasch, E 1988 Mood and memory changes in asthmatic children receiving corticosteroids. J Am Acad Child Adolesc Psychiatry 27:720-725

36. Igarashi $\mathrm{H}$, Inomata $\mathrm{K}$. Tateno A 1989 The effect of methotrexate on the development of synapses in the neonatal rat hippocampus. Neuropediatrics 20:196-198

37. Packan DR. Sapolsky RM 1990 Glucocorticoid endangerment of the hippocampus: tissue, steroid and receptor specificity. Neuroendocrinology 51:613618

38. Sapolsky RM, Krey LC, McEwen BS 1985 Prolonged glucocorticoid exposure reduces hippocampal neuron number: implications for aging. J Neurosci 5:1222-1227

39. Bayer SA, Yackel JW, Puri PS 1982 Neurons in the rat dentate gyrus granular layer substantially increase during juvenile and adult life. Science 216:890892

40. Clavelt LA, Gelber RD, Cohen HJ, Hitchcock-Bryan S, Cassady JR, Tarbell NJ. Blattner SR, Tantravahi R, Leavitt P. Sallan SE 1986 Four-agent induction and intensive asparaginase therapy for treatment of childhood acute lymphoblastic leukemia. N Eng! J Med 315:657-663

41. Niemever CM, Gelber RD. Tarbell NJ, Donnelly M. Clavell LA. Donahue K. Blattner SR. Cohen HJ, Sallan SE 1991 Low dose versus high dose methotrexate during remission induction in childhood acute lymphoblastic leukemia. Blood 78:2514-2519

42. Billett AL, Gelber RD, Tarbell NJ, Barr R, Blattner S, Clavell L, LeClerc JM Lipton J, Schwenn M. Schorin M. Cohen HJ, Sallan SE 1993 Sex differences in the risk of central nervous system (CNS) relapse in childhood acute lymphoblastic leukemia (ALL). Proc Am Soc Clin Oncol 12:317(abstr 1045)

43. Legraverend C. Mode A. Wells T. Robinson I, Gustafsson J-A 1992 Hepatic 
steroid hydroxylating enzymes are controlled by the sexually dimorphic pattern of growth hormone secretion in normal and dwarf rats. FASEB $\mathrm{J}$ 6:711-718

44. Argente J, Chowen JA, Zeitler P. Clifton DK. Steiner RA 1991 Sexual dimorphism of growth hormone-releasing hormone and somatostatin gene expression in the hypothalamus of the rat during development. Endocrinology 128:2369-2375

45. Painson J-C, Tannenbaum GS 199! Sexual dimorphism of somatostatin and growth hormone-releasing factor signaling in the control of pulsatile growth hormone secretion in the rat. Endocrinology 128:2858-2866

46. Geyer JR, Taylor EM, Milstein JM. Shaw CM, Hubbard BA, Geraci JP, Thornquist M, Bleyer WA 1988 Radiation, methotrexate and white matter necrosis: laboratory evidence for neural radioprotection with preirradiation methotrexate. Int J Radiation Oncol Biol Phys 15:373-375

47. Balsom WR. Bleyer A. Robison LL. Heyn RM. Meadows AT. Sitarz A, Blat J. Sather HN. Hammond GD $199 \mathrm{i}$ Intellectual function in long-term survivors of childhood acute lymphoblastic leukemia: protective effect of pre-irradiation methotrexate? A Childrens Cancer Study Group study. Med Pediatr Oncol 19:486-492

48. Bleyer WA, Fallavollita J, Robinson L, Balsom W, Meadows A. Heyn RM Sitarz A. Ortega J, Miller D. Constine L. Nesbit M. Sather H. Hammond D 1990 Influence of age, sex, and concurrent intrathecal methotrexate therapy on intellectual function after cranial irradiation during childhood. Pediatr Hematol Oncol 7:329-338 